libraries, and we can afford to travel. Third, we have all the conveniences of rapid communication- every institute has either fax or e-mail, both of which are very reliable.

In contrast, there are countries, mostly poor ones, with only one or two IAU members. Colleagues in this situation are obviously isolated. Not only do they have few contacts with their compatriots, but political, geographic and economic barriers often mean that contacts with colleagues elsewhere are few and difficult. Astronomy is low on the scale of their governments' priorities and is allotted so little money that no current journals at all can be bought. Finally, fax and e-mail are either nonexistent or unreliable. While this last disadvantage may be removed in the fairly near future, it is at present a real problem.

There are many countries between these extremes where colleagues have overcome the difficulties of relative isolation and made significant contributions to astronomy. The extremes serve to illustrate, however, how much some of us are privileged in comparison to colleagues for whom it is a major achievement to get a paper published at all. We can easily underestimate these colleagues because we so easily forget the difficulties under which they work. Programmes run by Commission 46, such as the ISYA and VLP are clearly valuable to our most isolated colleagues. Gifts of journals can also help. Don't wait until you retire to give away your lifetime collection - useful though such a gift can be. Try sending current volumes as they are completed. You can consult library copies, colleagues in many countries cannot.

\title{
THE TEACHING OF ASTRONOMY: PSYCHOLOGICAL-EDUCATIONAL CONSIDERATION
}

Joseph Nussbaum

Michlalah - Jerusalem College, P.O. Box 16078, Jerusalem, Israel

My task here is to present some thoughts regarding the teaching of introductory astronomy. These thoughts evolve from a broader framework currently prevailing amongst science education professionals. The main concern of this framework is finding ways of bridging and matching between the personal meaning of the learner and the accepted scientific meaning, regarding an area of knowledge.

What makes learning meaningful? When a person encounters a new body of knowledge and he/she attempts to acquire it, this knowledge will become 'meaningful' to him/her only when it is integrated with relevant knowledge already held by that person. Integrating (internalizing) new knowledge means establishing, in the student's mind, connections between elements of the new knowledge and related elements of existing knowledge. To become more meaningful, these connections should also constitute an extension and elaboration of the hierarchical structure of existing knowledge. Hierarchical structure, here, means that concepts, principles, 
general views and general belief are understood, by the student, as being different and more inclusive than specific facts, terms, names, formulae, etc. The more previously held knowledge is hierarchical in nature, the easier it is for the student to integrate new knowledge into proper places of that structure. So far we have described how personal meaning is achieved. If previously held knowledge includes basic misconceptions, the learning will still be meaningful, but the student's final conceptions will not be the desired ones (Nussbaum, 1986, 1990). The educational challenge is to ensure that the student's personal meaning will be compatible with the scientific one.

The problem in teaching astronomy is that generally we cannot build on 'a proper' knowledge that the learner holds, because there is much ignorance in the public regarding astronomy. More than that, quite often previously held knowledge includes elements that are preventing desired understanding of new material rather than promoting it. The astronomy teacher (at all levels) should be aware of these factors and design the teaching accordingly. Besides the dependence of meaningful learning of basic astronomy on previously held knowledge and its degree of hierarchical structure, meaningful learning depends also on the student's ability for spatial visualization, known also as 3-dimensional reasoning. This cognitive operation is especially required in astronomy since the essence of astronomy is the coordination of various perspectives of positions in space and more seriously - the analysis of several combined motions as seen from one perspective.

Regarding already held knowledge, one should differentiate between elements which are of various degrees of inclusiveness and abstractness.

(a) Observational facts and terms: Astronomy teaching can start only on the basis of a certain minimal body of observational knowledge, such as: the sun's daily and yearly path; the daily motion of stars; the path and motion of planets; what is angular distance; zenith; meridian, etc. Modern man is usually ignorant of these essentials. Except for rare cases, it is impossible to carry out outdoor night observation with students. A way to overcome it is to use efficient and simple simulation of celestial phenomena such as dynamic use of overhead projection transparencies (Nussbaum, 1990; Szostak, 1990), portable planetarium (such as STARLAB) and computer programs (Ch. 5 in Pasachoff \& Percy (Eds.), 1990). The simulation should involve extensive students' activities that would demand students to exercise their 3-D reasoning.

(b) Concepts and notions: Students' preconceptions and notions could be of a kind that support desired meaningful learning or of a kind that interfere and distort it. If the student acquired some proper notion of, for example, inertia, the relation between force and motion, gravity, then explaining more complicated phenomena will be easy. However, if the student strongly holds misconceptions, such as Aristotelian views about force and motions or that gravity works only where there is air (thus not in outer space), then proper understanding in further learning is risked. The implications are that (a) the teacher (at all levels) should be aware of his/her students' prior notions, and (b) he/she should address such misconceptions explicitly employing proper methods to initiate and encourage 'conceptual change' in the students (Nussbaum 1982, 1989).

(c) World views and beliefs: These are more essential and inclusive than the 
concepts and notions mentioned above. Such are views which hold that: space is infinite (or alternatively, finite); every physical phenomenon has a physical cause (or alternatively holding that sometimes phenomena do not have a physical cause); the physical world can be investigated while using a rational approach (or alternatively can be approached mystically); matter and energy are universally conserved (or not universally). We know that alternative world views were responsible in the history of science for various basic approaches and theories. World view and beliefs can also influence students' personal meaning of school knowledge. Thus, the teacher should see as part of his/her role the initiating and encouraging accommodation of world views, at least in the context of science learning.

Another kind of general view is related to the very nature of human knowledge and the nature of science. The classical view has been that true knowledge is a successful discovery of an existing element of reality. The currently held view is that knowledge is an intellectual construct - a model that serves our need for understanding but can never be proven as true. This nature of scientific knowledge is most clearly represented in astronomy. Students should understand that the heliocentric view is not simply a truth but is a model which is better than the geocentric one, but it remains a model.

The major recommendation that I arrive at when considering all the above factors is the use of the historical approach on the high school and college level (Nussbaum, 1990). The historical approach has the following advantages:

1. It enables the gradual building of observational knowledge, while reviewing various periods, and exercising 3-D reasoning at each stage. The current terminology for observational knowledge is still given from geocentric perspectives and the ancient model is a good device to present (assuming that it will be replaced later by the heliocentric one).

2. It deals indirectly with students' misconceptions since these resemble, in their elements, historical conceptions. Presenting explicitly and elaborately the historical alternatives is likely to help the student to clarify for him/herself what his/her own conceptions are and clarify the alternatives. The historical presentation allows the time required for the digestion of the new knowledge and for accommodating misconceptions.

3. It invites naturally a discussion of alternative world views and beliefs and so teaches the student an important lesson about the nature of science.

4. It presents knowledge as ever evolving and changing and as constituting the best intellectual construct at each point in time.

Nussbaum, J. 1986, "Students' perception of astronomical concepts". Proceedings of the GIREP Conference "Cosmos - An Educational Challenge", Copenhagen.

Nussbaum, J. 1989, "Classroom conceptual change: philosophical perspectives". International Journal of Science Education, 11:530-540.

Nussbaum, J. 1990, "Astronomy teaching: challenge and problems". Proceedings of the IVth International Conference of "Teaching Astronomy". Organized by the Universitat Politecnica de Catalunia, Barcelona.

Nussbaum, J. and Novick, S. 1982, "Alternative frameworks, conceptual conflict and accommodation: Toward a principled teaching strategy." Instructional Science, 
11:183-200.

Pasachoff, J.M. and Percy, J.R. (Eds.) 1990, The Teaching of Astronomy. Proceedings of the 105th Colloquium of the International Astronomical Union, Williamstown, MA. July 1988. Chapter 5: Computers, pp. 159-188. Cambridge University Press, Cambridge.

Szostak, R. 1990, "Two innovative devices for the teaching of astronomy" in Pasachoff and Percy (Eds.), The Teaching of Astronomy. Proceedings of the 105th Colloquium of the International Astronomical Union, Williamstown, MA. July 1998. pp. 218-222.

\title{
ASTRONOMY IN THE SCHOOLS: THE EUROPEAN SYSTEM
}

\author{
Lucienne Gouguenheim \\ Observatoire de Paris-Meudon, F-92195 Meudon, Cedex, France \\ E-mail: gouguenheim@obspm. fr
}

The following teaching activities and materials described hereafter, come from: (1) France, Comité de Liaison Enseignants et Astronomes (CLEA), (2) Germany, University of Münster (Roland Szostak, hereafter RS), (3) Spain, University of Catalogna Institut de Ciencias de l'Educacio (Rosa Maria Ros, ICE, (4) United Kingdom, Open University (OU) and (5) United Kingdom, a science centre in Northampton (Simply Space). Strikingly, these different groups suggest similar activities, based on observations and experiments aimed at studying the same concepts.

\section{ELEMENTARY SCHOOL AND JUNIOR HIGH SCHOOL}

1.1 Structure of space and time. A device which was invented by Roland Szostak is widely used now, both in Germany and France. A half-sphere made of glass or transparent plastic about $40 \mathrm{~cm}$ in diameter (it could be also a salad bowl) is set horizontally on a cardboard; the edge represents the horizon circle; right at the centre of the horizon circle, a small white paper is stuck which will be the target. The whole device is then set in a place that will be exposed to the Sun's light for the whole day and the meridian that was marked off on the plate will be aligned along the actual meridian using a compass. A small rectangular piece of cardboard with a small hole at the centre will be moved on the surface of the half-sphere in the approximate direction of the Sun. It casts a shadow on the ground of the model and a small luminous spot can be seen in the centre. The piece of cardboard must then be moved over the surface until the luminous spot falls right onto the target. The exact position of the hole will then be marked off with a felt-tip pen. The time of observation should also be recorded. In that way, several recordings of the Sun's position will be made at different times during the day. At the end of the day, all the points will 